\title{
CRENÇAS ENVOLVENDO O NÃO APRENDER: UM ESTUDO EVOLUTIVO SOBRE A CONSTRUC̣̃̃O DO CONHECIMENTO SOCIAL
}

\author{
Eliane Giachetto Saravali* \\ Taislene Guimarães** \\ Karina Perez Guimarães*** \\ Ana Paula Melchiori****
}

RESUMO: A construção do conhecimento social, sob o enfoque piagetiano, vem sendo alvo de pesquisas recentes no contexto brasileiro. Nessa perspectiva, o presente artigo traz dados parciais de um estudo evolutivo a respeito das ideias de crianças e adolescentes sobre a não aprendizagem. Apresentamos aqui os dados obtidos a partir do segundo instrumento metodológico utilizado na pesquisa: a análise de uma história envolvendo uma situação de não aprendizagem, aplicado em 80 escolares entre 06 e 16 anos. Os principais resultados indicam que a maioria dos sujeitos tende a responsabilizar somente os alunos pela não aprendizagem, justificando-a por meio de fatores como desinteresse, indisciplina, entre outros. As crenças dos sujeitos são analisadas também conforme os níveis de compreensão da realidade social e se apresentam, para a maioria deles, no nível mais elementar.

Palavras-Chave: Conhecimento Social; Estudo Evolutivo; Aprendizagem.

\footnotetext{
* Doutora em Educação pela Universidade de Campinas (UNICAMP); Docente do Departamento de Psicologia da Educação e do Programa de Pós-Graduação em Educação da Universidade Estadual Paulista Julio de Mesquita Filho (UNESP/Marília). E-mail: eliane.saravali@marilia.unesp.br

** Mestre em Educação pelo Programa de Pós-Graduação em Educação da Universidade Estadual Paulista Julio de Mesquita Filho (UNESP/Marília); Docente da rede municipal de ensino de Marília-SP. E-mail: taislene_ped@yahoo.com.br.

** * Doutora em Educação pela Universidade de Campinas (UNICAMP); Docente e Coordenadora dos Cursos de Pedagogia e Psicopedagogia das Faculdades Integradas de Mirassol (UNIESP). E-mail: pgkarina@hotmail.com

*** * Especialista em Psicopedagogia pela União das Escolas do Grupo Faimi de Educação (UNIFAIMI); Docente da Universidade Estadual Paulista Julio de Mesquita Filho (UNESP/São José do Rio Preto). E-mail: anapaula_melchiori@terra.com.br
} 


\section{BELIEFS INVOLVING NOT LEARNING: \\ AN EVOLUTIONARY STUDY ON THE SOCIAL CONSTRUCTION OF KNOWLEDGE}

ABSTRACT: The construction of the social knowledge, under the Piagetian approach, has been the target of recent research in the Brazilian context. From this perspective, this article presents preliminary data from an evolutionary study regarding the ideas of children and adolescents about not learning. Here we present data obtained from the second methodological tool used in this research: an analysis of a story involving a situation of not learning, applied to 80 students between 06 and 16 years. The main results indicate that most of the students tend to blame only themselves for not learning. They justify it by factors such as indifference, indiscipline, among others. The beliefs of the students are also analyzed according to levels of understanding of social reality and the majority of the students demonstrate a very elementary level of understanding. Keywords: Social Knowledge; Evolutionary Study; Learning.

\section{Aspectos Teóricos}

$\mathrm{O}$ artigo apresenta dados parciais de uma pesquisa ${ }^{1}$ a respeito da construção do conhecimento social na perspectiva piagetiana, em específico, sobre as ideias de crianças e adolescentes referentes a não aprendizagem.

A construção do conhecimento social não foi tão explorada na obra piagetiana, como o foi a construção dos conhecimentos físico e lógico-matemático. Embora em alguns estudos, Piaget aborde questões sociais $(1967$; 1979) como a ideia de família, o conceito de país, as crenças sobre as origens dos nomes das coisas, entre outros, o faz sob a ótica da construção do raciocínio lógico. Nesse sentido, podemos exemplificar a noção de causalidade, analisada no caso das relações de parentesco, e a noção de parte e todo, para o conceito de país.

A maioria destes conteúdos é estudada, na atualidade, por pesquisadores contemporâneos que deram sequência às pesquisas piagetianas, sob a ótica do conhecimento social. Mesmo que Piaget não tenha adotado o termo conhecimento social ao se referir a essas noções, ele trabalha o conceito de inteligência verbal como forma geral de elaboração das mesmas. Nesse sentido, percebemos que ao tratar da inteligência verbal, o autor refere-se a uma elaboração própria do indivíduo, não descartando as transmissões sociais necessárias, sem, todavia, atribuirlhes um caráter determinante. 
Chamamos, com efeito, de inteligência verbal à função de adaptação da criança, não à realidade em si mesma, mas às palavras e às expressões ouvidas da boca dos adultos ou de outras crianças, e sob as quais a criança procura imaginar uma realidade. Justamente porque a inteligência verbal, em parte, se destaca do real, o pedagogo não deve cultivá-la na criança, pelo menos sem precauções indispensáveis. Para o psicólogo, no entanto, ela é de grande interesse: o esquematismo do pensamento infantil mostra-se, frequentemente, mais a descoberto na inteligência verbal do que a propósito de representações concretas. A criança sente-se completamente livre, por exemplo, quando ouve a palavra "país" de dar a ela a representação que quiser. Esta representação, na verdade, depende muito menos do que se possa imaginar das influencias ambientais: o que a criança ouviu, não estando ligado a nenhuma representação concreta, é deformado e selecionado segundo as leis do pensamento próprio de cada uma das faixas etárias da criança. (PIAGET, 1967, p.116-117).

Piaget também mencionava que o desenvolvimento psicológico, que conduz a criança ao pensamento adulto, “[...] não dependeria unicamente de fatores psico-biológicos hereditários, nem simplesmente da pressão do mundo físico sobre o espírito, mas, sobretudo, da influência da vida social sobre o indivíduo." (PIAGET, 1976, p.12).

As questões envolvendo o contexto social, na teoria piagetiana, também podem ser encontradas na clássica obra sobre o desenvolvimento do juízo moral (PIAGET, 1994). Ali estão contidas as reflexões sobre a importância das interações e das trocas entres os indivíduos.

Assim é que Piaget nos apresenta o desenvolvimento moral em fases, caracterizadas pelo estabelecimento de relações diferentes com as normas sociais e com os outros (adultos e/ou crianças). Nesse sentido, temos um estágio de ausência de regra social, característico da criança bem pequena, que denominamos de anomia. Conforme a inserção no mundo social e no mundo dos adultos ocorre, a criança, então, passa por um estágio de heteronomia. Tal estágio, necessário para a construção do seguinte, caracteriza-se pelo respeito unilateral às normas, pela obediência cega às imposições adultas e/ou de crianças mais velhas. No último estágio, o do desenvolvimento moral autônomo, as regras tornam-se legítimas não porque emanam da autoridade, mas porque são interessantes e importantes para todos os envolvidos naquela situação. Por isso, nessa fase, observamse o estabelecimento dos "contratos sociais", o que será permitido ou não é fruto dos acordos do grupo, bem como imperam os jogos de regras que implicam em mútuas coordenações e no respeito às normas combinadas. 
A tarefa de avançar nos estudos e pesquisas específicos sobre o conhecimento social ficou para os seguidores do mestre genebrino, entre eles, destacamos o espanhol Juan Delval (1989; 2002; 2007) que vem conduzindo pesquisas em diferentes países e a respeito de questões específicas sobre o mundo social. Delval é hoje, também, o pesquisador que mais influencia os estudos realizados no contexto brasileiro (ASSIS, 2003; SARAVALI, 2005; GUIMARÃES, 2012).

$\mathrm{O}$ aspecto que nos parece essencial ao considerarmos a compreensão de noções sociais, a partir do enfoque piagetiano, é analisar o papel individual que cada sujeito realiza ao interagir com esses conteúdos. Como explica Delval (2007), essa é a marca da concepção construtivista sobre a construção do conhecimento social - o papel do sujeito. Esse papel não pode ser esquecido, sobretudo, quando percebemos, pelos resultados das pesquisas, crenças bastante curiosas que as crianças apresentam e que são diferentes das dos adultos e daquilo que existe de fato no meio social. Soma-se a isso o caráter universal destas crenças, isto é, muitos pesquisadores encontram respostas semelhantes ao realizarem pesquisas sobre as representações de aspectos específicos da realidade social em ambientes sociais diferenciados.

A criança, a partir dos elementos advindos dos adultos, constrói uma representação do mundo social, unindo esses elementos à suas próprias observações. O resultado desse processo é a formação de conceitos e teorias próprias, divergentes das dos adultos e semelhantes em crianças de diferentes países e meios sociais. (DENEGRI, 1998).

A partir das inúmeras investigações que realizou, pesquisando diferentes aspectos e conteúdos da realidade social, Delval (2002) propôs que os indivíduos se apropriam destes conteúdos percorrendo três estágios ou níveis de compreensão.

Num primeiro nível, encontrado até os 10-11 anos, os sujeitos se baseiam sempre nos aspectos mais visíveis das situações em questão, desconsiderando processos ocultos e subjacentes, tão comuns em questões sociais. Apresentam também dificuldades em coordenar perspectivas diferentes, bem como em considerar a existência de conflitos. As explicações desse nível "baseiam-se nas aparências, no que é mais visível, no que se percebe diretamente. Os fenômenos sociais apoiam-se em imagens pouco conectadas entre si e bastante estereotipadas" (DELVAL, 2002, p.224). Há, portanto, uma compreensão parcial da realidade. 
Em relação ao segundo nível, que se estende dos 10-11 anos aos 13-14 anos, Delval (2002) explica que os sujeitos começam a levar em conta aspectos não visíveis das questões analisadas e começa a aparecer a consideração de processos que devem ser inferidos, pois estão inicialmente ocultos. Há uma percepção maior dos conflitos, embora a coordenação de diferentes pontos de vista seja algo ainda difícil de ocorrer.

No terceiro nível, cujo início ocorre por volta dos 13-14 anos, observa-se, nas explicações dos sujeitos, que os processos ocultos, bem como as diferentes possibilidades de uma mesma situação passam a ser considerados. Os sujeitos estão de posse de mais informações sobre o meio social, mas aqui conseguem relacioná-las e integrá-las num sistema mais coerente. "Os sujeitos se tornam muito mais críticos em relação à ordem social existente, emitem juízos sobre o que é certo e o que não é e propõem soluções alternativas" (DELVAL, 2002, p.231).

No contexto brasileiro, podemos destacar os seguintes estudos realizados sobre diferentes conteúdos da realidade social: Tortella (1996, 2001) observou a evolução das representações das crianças sobre a amizade; Godoy (1996) investigou as ideias infantis sobre a etnia; Barroso (2000), Trevisol (2002) e Saravali (2005) pesquisaran a respeito da evolução do conceito de direito; Borges (2001) explorou o conceito de família; Cantelli (2009) pesquisou a educação econômica; Baptistella (2001) analisou a compreensão de um comercial televisivo; Braga (2003) e Guimarães (2012) trabalharam com as representações acerca do meio ambiente; Pires e Assis (2005) e Othman (2006) investigaram a compreensão a respeito da noção de lucro; Araújo (2007) estudou o desenvolvimento do pensamento econômico; Silva, M.O. (2009) pesquisou questões relacionadas ao trabalho e gênero; Pieczarka (2009) investigou aspectos relacionados a desigualdade social e a mobilidade socioeconômica; Araújo e Gomes (2010) exploraram as crenças sobre a mobilidade social, Monteiro (2010) pesquisou questões relacionadas às representações sobre a violência urbana.

O que se nota, em todas essas pesquisas, é que os sujeitos apresentam crenças bastante singulares e específicas sobre conteúdos cotidianos do mundo social. Isso demonstra o árduo processo percorrido na busca de uma compreensão mais elaborada da realidade social.

Os estudos brasileiros se caracterizam mais por abordagens exploratórias e delineamentos evolutivos do que por processos de inter- 
venção, sobretudo aqueles voltados a questões pedagógicas. Em relação a aspectos da realidade escolar, como por exemplo, a escola, o professor e a aprendizagem, destacamos os trabalhos de Cantelli (2000) e Guimarães (2007).

O trabalho de Cantelli (2000) apresenta um estudo evolutivo das representações de escolas em crianças e adolescentes, especificamente a compreensão da origem da escola, seu objetivo e as funções de seus profissionais. Seus resultados apontaram para uma evolução da compreensão desses aspectos que vai desde um nível mais elementar no qual, por exemplo, as crianças acreditam que havendo carteiras, paredes e outros itens físicos, tem-se uma escola, até níveis mais elaborados no qual os adolescentes, por exemplo, avaliam a qualidade e as condições do ensino ofertado pela instituição. Nesse estudo, chama a atenção o fato de que, mesmo em idades mais avançadas, poucos sujeitos apresentaram respostas características do nível mais elaborado de compreensão da realidade social, ou seja, o nível III citado anteriormente e encontrado por Delval (2002) e seus colaboradores a partir dos 13-14 anos.

Guimarães (2007) realizou um estudo sobre as ideias de 52 crianças entre 7 e 8 anos acerca da escola e do professor, inseridas em dois ambientes educacionais diferentes: um considerado como sóciomoral construtivista, permeado por relações de cooperação e respeito mútuo, e o outro considerado como tradicional, no qual eram priorizadas a coação e o respeito unilateral. Os resultados demonstraram que os sujeitos não possuíam uma real compreensão da função da escola e do professor, apresentando crenças bastante elementares, independente do ambiente escolar ao qual pertenciam.

Um aspecto interessante da realidade social e, principalmente escolar, refere-se aos problemas de aprendizagem.

Embora o campo de estudo referente às dificuldades de aprendizagem seja bastante ambíguo e confuso, tal o grande número de definições e caracterizações, muitos alunos tem sido facilmente encaminhados por seus professores e escolas, aumentando uma longa demanda de atendimentos especializados.

Tais fatos nos fazem crer que nossos estudantes se deparam com isso constantemente, observando em si próprios, nos colegas e/ou nos professores questões relacionadas a situações de não aprendizagem 
ou dificuldades de aprendizagem. Esse é um aspecto da realidade social com o qual os alunos se relacionam quotidianamente. Isso significa que questões envolvendo o aprender e o não aprender fazem parte do cotidiano escolar de nossos estudantes, podendo, muitas vezes, referirem-se a eles próprios.

Alguns trabalhos abordaram esse tema, embora sob óticas diferentes da que nos propomos aqui. Nestas pesquisas, geralmente, são investigadas populações menores, com praticamente a mesma faixa etária e com características específicas como, por exemplo, Silva, A.P.F. (2009) que analisou questões relacionadas ao fracasso escolar, à indisciplina e à evasão escolar na perspectiva do aluno pobre; ou ainda o trabalho de Sirino (2002) que pesquisou alunos de uma terceira série, taxados como crianças com problemas de aprendizagem. Os resultados apontam, em comum, que os alunos possuem crenças na sua própria incapacidade.

Há também estudos realizados sob o enfoque da Teoria das Representações Sociais de Serge Moscovici (1978). Entre eles, as pesquisas de Corsini (1998), Camargo (2005), Mariano (2009) e Osti (2010) apontam uma tendência dos alunos relacionarem a questão da não aprendizagem a esforço próprio e/ou a atributos pessoais.

Portanto, embora haja estudos sobre temáticas semelhantes, não encontramos trabalhos, sob o enfoque construtivista da construção do conhecimento social, referentes, especificamente, à aprendizagem e a não aprendizagem. Nesse sentido, o presente trabalho buscou, entre outros, investigar como evolui e se constituem as ideias acerca da não aprendizagem. Pretendeu-se avaliar a compreensão e elaboração dessas questões pelos sujeitos ao longo do desenvolvimento, mediante a realização de um estudo evolutivo, analisando a existências de possíveis mudanças nas formas de se interpretar a temática.

\section{Aspectos Metodológicos}

A presente pesquisa ${ }^{2}$ teve como objetivo central investigar as ideias encontradas em crianças e adolescentes a respeito do não aprender. Constitui-se num estudo evolutivo transversal baseado no método clínico-crítico piagetiano (PIAGET, 1979). Segundo Delval (2002, p.47): 
"Quando realizamos um estudo evolutivo, o que nos interessa é observar como uma conduta, uma determinada capacidade ou uma representação vai mudando ao longo do tempo".

Participaram desta pesquisa 80 escolares entre 06 e 16 anos de escolas públicas de cidades do interior do estado de São Paulo, que foram escolhidos aleatoriamente. Como se trata de um estudo evolutivo, a faixa etária escolhida abrange um longo período do desenvolvimento na intenção de observar possíveis diferenças e/ou avanços, bem como evoluções na maneira como as crianças e adolescentes respondem às questões. $\mathrm{O}$ número de participantes e a divisão da faixa etária foram definidos com base nas orientações de Delval (2002) e correspondem ao que segue: 20 sujeitos de 06 anos, 20 de 09 anos, 20 de 12 anos e 20 de 16 anos.

Os recortes nessas idades procuraram respeitar aqueles propostos por Delval (2002) em relação aos níveis de compreensão do mundo social. Dessa forma, como o primeiro nível se estenderia até os 10-11 anos, optamos por trabalhar com dois momentos do desenvolvimento: um mais característico do período pré-operatório (6 anos) e outro característico das operações concretas (9 anos) ${ }^{3}$, para o segundo nível, trabalhamos com sujeitos de 12 anos, que podem estar em equilíbrio das operações concretas e/ou início das operações formais e, do terceiro nível, sujeitos de 16 anos (operações formais).

Todavia, é importante ressaltar que não realizamos nenhum tipo de avaliação que pudesse definir aspectos relacionados ao desenvolvimento cognitivo dos nossos participantes, portanto, não sabemos em que momento do desenvolvimento eles se encontravam. Somente a construção do conhecimento social foi avaliada, embora acreditemos que a pesquisa dessas relações (desenvolvimento cognitivo e conhecimento social) seja importante e útil para a compreensão dos processos percorridos para compreensão do mundo social.

Os sujeitos foram submetidos a três procedimentos metodológicos: a realização de um desenho que retratasse uma pessoa que aprende e outra que não aprende, a análise de uma história, envolvendo uma situação de não aprendizagem e a interpretação de um curtametragem, retratando a história de uma criança que tem dificuldades em acompanhar as atividades de matemática desenvolvidas numa sala de aula. 
Em todas as etapas da pesquisa foi utilizado o método clínicocrítico piagetiano (PIAGET, 1979) que tem por característica os desdobramentos de uma questão em outras não programadas. Optamos pelo uso desse método, por acreditarmos que ele nos forneça mais condições de nos aproximarmos do pensamento infantil e da forma como a criança e o adolescente agem e pensam a resolução de desequilíbrios e conflitos.

A pesquisa tem uma abordagem qualitativa e a análise dos dados foi realizada mediante a interpretação das respostas dadas pelos sujeitos que indicam níveis de compreensão da realidade social (DELVAL, 2002).

Em função dos limites desse artigo, apresentaremos aqui o segundo instrumento utilizado - a análise da história.

\section{Os resultados}

Embora não traga elementos de juízo moral, a história é semelhante àquelas utilizadas por Piaget no livro "O Juízo Moral na Criança" (1994) e as utilizadas por Delval e sua equipe (DELVAL; PADILLA, 1997) nas pesquisas sobre os direitos das crianças. A história completa é a seguinte:

O aluno Marcelo (de idade igual a do sujeito a ser questionado), não consegue aprender as lições que a professora ensina. Todos os dias ele não consegue copiar a matéria da lousa, não entrega as lições de casa e não resolve os problemas propostos pela professora. O que você acha dessa situação? $\mathrm{O}$ que você acha que está acontecendo com esse aluno? Quem poderia ajudá-lo? E a escola? E a professora? Por que será que ele não aprende? $\mathrm{O}$ que você acha que a professora poderia fazer? O que você acredita que deve ser feito? E se ele não aprender o que vai ocorrer? Você conhece alunos assim? Como eles são? O que acontece com eles? Como você se sente diante de situações assim?

O objetivo da utilização desse procedimento metodológico foi verificar como os sujeitos interpretavam a situação de não aprendizagem, como viam as possibilidades de ação docente e o papel da escola na história proposta. Para facilitar a apreciação das respostas dos sujeitos e considerando as interpretações apresentadas por eles, bem como os elementos que eram trazidos para a discussão, a análise da história foi subdividida em 5 eixos temáticos, a saber: 
1. Caracterização do problema - Esse eixo se refere às perguntas que permitem ao sujeito identificar e justificar o problema apresentado na história. Algumas delas ${ }^{4}$ O que está acontecendo com a criança? Por que ela não consegue fazer ou não aprende?

2. Resolução - Aqui são analisadas as crenças que os sujeitos possuem sobre como a situação colocada pela história pode ser resolvida. Nesse sentido, podemos perceber o papel que o professor, a escola e os demais envolvidos assumem para os entrevistados. Algumas perguntas referentes a esse eixo temático: Quem poderia ajudá-lo? E a escola? E a professora? O que você acha que a professora poderia fazerer? O que você acredita que deve ser feito?

3. Desfecho - Neste eixo são analisadas as interpretações a respeito do desenlace da história, isto é, o que ocorrerá se a aprendizagem não se efetivar. A pergunta aqui analisada foi: E se ele não aprender o que vai ocorrer?

4. Realidade - Fazem parte desse eixo as perguntas referentes ao conhecimento real de alunos, em comparação com a situação apresentada na história. Entre as perguntas feitas: Você conbece alunos assim? Como eles são? O que acontece com eles?

5. Sentimentos - Aqui estão as respostas que os sujeitos apresentam sobre como se sentem diante de situações de não aprendizagem. A pergunta feita foi: Como você se sente diante de situações assim?

No presente artigo, exploraremos o eixo 1 - a caracterização.

Conforme dito anteriormente, nesse eixo buscou-se analisar como os participantes da pesquisa identificam/justificam/explicam o problema apresentado na história. A análise inicial identificou a existência de algumas categorias de respostas.

Numa primeira categoria, estão as atribuições para a não aprendizagem, do personagem da história, relacionadas à indisciplina, tais como: bagunçar, não prestar atenção etc. Essa indisciplina referese ao aluno Marcelo, ou seja, é ele que a comete. Vejamos alguns exemplos: 
HEl (6;10): O que você acha dessa situação? Que ele tem que olhar na lousa e apren... Que ele não tem que conversar. [...] E não ficar brincando com os colegas na hora de... de escrever e de desenhar.

LFS (6;5): E por que será então que você acha que ele não aprende? Porque ele far muita arte.

BEK (9;4): E por que será que ele não aprende? Porque ele fica conversando com os alunos e perde tempo.

CXS (9;1): Eu acho que... que ele fica muito atrasado, ele não consegue copiar porque na hora que a professora vai apagar, ai ele tava brincando na hora que a professora tivesse explicando pra ele poder fazer a tarefa de casa e ele tava brincando e por isso que ele não conseguia copiar nada da lousa e fazer a tarefa em casa.

AMA $(9 ; 9)$ : Por que será que ele não aprende? Tipo, porque a professora tá sempre na lousa explicando e ele tá sempre conversando na hora que ela tá explicando e nunca pode lembrar de nada e isso é por pouca causa, ele vai no lixo apontar o lápis e o lápis já tá com a ponta apontada.

CFR (12;11): O que você acha que está acontecendo com ele? [...] Muitas vezes ele fica brincando na sala enquanto o professor explica.

FEF (12;11): [...] por que será que isso acontece com ele? Porque ele conversa com outras pessoas... Ele conversa demais...

BRE (16;8): E por que será que ele não aprende? Por que será que ele não aprende? Deve ficar voando com a cabeça, voando no mundo da lua [...].

KAI (16;6): Eu acho uma situação que tem que prestar mais atenção o aluno tem que prestar mais atenção, falta de atenção.

$\mathrm{Na}$ segunda categoria, estão as crenças que relacionam a não aprendizagem do aluno Marcelo em função de aspectos motivacionais, como não querer, não gostar ou estar desinteressado. Alguns exemplos:

CLL (6;8): E por que será que ele não aprende? Porque né às vezes ele não gosta de... de fazer letrinhas e aprender. 
$\operatorname{HAR}(6 ; 9)$ : Porque ele não gosta de aprender.

MUR (6;9): Porque ele não quer aprender, se ele quisesse ele conseguia.

GGF (9;2): O que você acha que está acontecendo com essa criança, com o Marcelo? Que ele tem preguiça. Por que será que ele não aprende? Porque ele não... não fica tentando.

KAT $(9 ; 10)$ : Por que será que ele não aprende? Porque ele nunca tentou aprender.

$\operatorname{LEB}(9 ; 11):$ Ele tem que se esforçar mais... pra aprender.

RMO (9;3): O que você acha que está acontecendo com essa criança? Com o Marcelo? Que ela não quer aprender nada.

BFG (12;4): O que você acha que está acontecendo com o Marcelo? Ele [...] não gosta de aprender as coisas assim... que a professora passa.

DEC (12;9): Ele não quer aprender.

MCC (12;5): [...] ele não aprende porque ele não quer, porque ele não liga. [...] Ab! Eu acho que ele não quer aprender que ele... que mais pra frente ele acha que não vai precisar disso [...].

JEA $(16 ; 10):$ O que você acha dessa situação? [...] que não se importa tanto com os estudos.

JUL (16;3): [...] pode ser que ele mesmo não quer... ele se nega a tentar aprender ele acha que não é capaz e se nega.

$\operatorname{KAR}(16 ; 4):$ [...] eu acho que falta vontade ou... não sei.

A terceira categoria se refere a explicações baseadas em problemas orgânicos e internos, que justificariam a não aprendizagem. É o caso de: 
DIV (6;2): Ele... ele devia usar óculos pra enxergar a letra. [...] por que você acha que ele não aprende? Porque ele é cego, né?

NAY (6;3): E por que será que ele não aprende? Porque eu acho que ele não tem muito é... muita... muita habilidade.

MAR (6;8): O que você acha que está acontecendo com essa criança? Que ele não ouve o que a professora tá falando, acho que ele tem problema de ouvido. Por que será que ele não aprende? Por causa do problema no ouvido dele.

$\operatorname{KAR}(9 ; 5):$ O que você acha que está acontecendo com essa criança que não consegue aprender? Ele tem algum problema, alguma coisa. Não sei qual. [...] Por que será que ele não aprende? Isso eu não sei. O que você acha que pode ser? Uma doença que não consegue escrever.

AEM $(12 ; 5):$ Por que você acha que ele não está aprendendo? $\grave{A s}$ vezes porque ele deve ter algum problema [...] Que tipo de problema você acha que poderia ter? Problema de cabeça [...].

MAV (12;9): [...] ele tem algum problema de não entender direito assim.

BIH (16;8): E por que será que ele não aprende? Ou por falta de capacidade [...] ou porque ele tem algum problema. Ah... Por exemplo, essa falta de capacidade o que seria? Ou problemas mentais [...] De deficiência.

A quarta categoria é composta de respostas que relacionam a não aprendizagem a questões familiares; assim, o personagem não aprende pois tem algum problema familiar que o atrapalha/impede. É o caso de:

VIT (9;8): Por que será que ele não aprende? Porque talvez tem algum problema em casa, também ele não quer, talvez a mãe dele não ajuda ele em casa, briga bastante pra ele ai tem algum problema em casa ai chega na escola ele fica estressado.

AEM $(12 ; 5):$ Por que você acha que ele não está aprendendo? $A$ s vezes porque ele deve ter algum problema [...] Que tipo de problema você acha que ele poderia ter? [...] problema familiar que afetam. 
BRE (16;8): E por que será que ele não aprende? [...] tá com algum problema em casa que tem muito aluno... muitas pessoas né que tá com problema em casa e são também assim não dá muita bola pro estudo.

GI0 (16;7): O que você acha dessa situação? Com certeza ele deve ter... tá tendo algum problema em casa. Por exemplo, o que ele pode ter? Ab! Ele deve andar brigando muito com a mãe dele com o pai dele...

Uma quinta categoria refere-se à indisciplina, porém, vinda dos outros colegas ou da própria classe de uma maneira geral. Essa indisciplina impediria a criança da história de aprender. Alguns exemplos:

JUI (12;9): O que você acha dessa situação? Que... não consegue entender porque a classe tem muito barulho.

MAV (12;9): Por que será que ele não está aprendendo? [...] porque ele tá escutando muita bagunça e não consegue entender nada, tá ligado naquilo mas tá escutando os outros e não consegue.

MBF (12;4): O que você acha que está acontecendo com essa criança, com o Marcelo? Ab! Amigos que ficam conversando com ele e incentivando ele fazer bagunça.

A sexta categoria que consideraremos aqui aparece nos protocolos de somente dois sujeitos. Estes participantes analisam o problema da criança da história considerando-o a partir da ação do professor. São os casos de:

GI0 (16;7): O que você acha que está acontecendo com esse adolescente? Ah! Ele... ele às vežes ele assim não ir pra frente, reprovar... nunca... nunca assim vai tentar ser alguém mas não vai conseguir porque ele não aprende ou às vezes pode ser o próprio professor um pouco também né que às vezes não sabe explicar assim pra ele do jeito que ele queria que aconteceria.

MHE (16;11): Por que será então que ele não está aprendendo? Então porque falta incentivo né, falta conversa. E você acha que falta incentivo por parte de quem? Por parte dos professores chegar e conversar. 
Finalizando, a última categoria agrupa as respostas do tipo "não sei" ou aquelas que não se enquadram em nenhuma outra categoria, denominadas "outros". Estas últimas são respostas isoladas que não chegam a compor crenças que poderiam ser apresentadas como uma nova categoria, visto que não aparecem em nenhum outro sujeito, nem mesmo de forma análoga.

MUR (6;4): O que será que está acontecendo com ele, com o Marcelo? Não sei. Você não sabe? Você nem tem ideia do que está acontecendo com ele? Não.

VIN $(6 ; 6):$ O que você acha que está acontecendo com essa criança? Acho que ele é pobre. Por que será que ele não aprende? Acho que ele não tem lápis.

LNA (16;9): O que você acha dessa situação? Então eu acho que ele podia perguntar mais porque todos os professores pelo menos aqui na escola eles falam se você não entendeu você pergunta e tem sempre aquele que tem vergonha de perguntar porque tem vergonha dos outros alunos, os outros amigos achar que ele é burro então ele fica com medo ele fica muito preso. Eu acho que ele devia perguntar mais [...]

A Tabela 1, a seguir, apresenta a quantificação das respostas dadas pelos sujeitos nas categorias do eixo "caracterização da história".

Tabela 1. Caracterização da não aprendizagem na história ${ }^{5}$

\begin{tabular}{|c|c|c|c|c|c|c|}
\hline \multirow[t]{2}{*}{ CATEGORIAS } & \multicolumn{4}{|c|}{ IDADES } & \multirow[t]{2}{*}{ TOTAL } & \multirow[t]{2}{*}{$\%$} \\
\hline & 6 & 9 & 12 & 16 & & \\
\hline 1. Indisciplina do aluno & 16 & 20 & 12 & 8 & 56 & 70,0 \\
\hline 2. Motivação & 8 & 10 & 8 & 16 & 42 & 52,5 \\
\hline 3. Problemas Orgânicos & 4 & 1 & 8 & 5 & 18 & 22,5 \\
\hline 4. Problemas Familiares & - & 1 & 3 & 9 & 13 & 16,3 \\
\hline 5. Indisciplina dos Colegas & - & - & 4 & - & 4 & 5,0 \\
\hline 6. Ação do Professor & . & . & . & 2 & 2 & 2,5 \\
\hline 7. Não sabe/outros & 6 & 2 & 1 & 4 & 13 & 16,3 \\
\hline
\end{tabular}


Em estudo realizado com adultos, professores e alunos de cursos de Psicopedagogia, Guimarães e Saravali (2006) e Saravali e Guimarães (2007) observaram que há uma tendência em se culpabilizar o aluno pela não aprendizagem, predominando justificativas sobre desinteresse, desmotivação, entre outros. Nossos dados também apontam esses mesmos aspectos, as crianças e jovens tendem a encontrar um culpado ou uma explicação para o não aprender que recai, na maioria das vezes, sobre um dos lados, no caso, o aluno.

É claro que as crianças falam daquilo que experenciam todos os dias e que, muitas vezes, pode se referir a si próprias. Conforme discutido anteriormente, essa é a marca da construção do conhecimento social, isto é, a união e atribuição de sentido àquilo que provém do ambiente e as próprias percepções e/ou elaborações.

Essas respostas que trazem os elementos individuais foram mais observadas na análise dos eixos 4 e 5 , realidade e sentimentos. Nesses eixos, foi possível identificar claramente verbalizações que aludiam àquilo que os próprios participantes já tinham vivenciado na sala de aula. Vejamos alguns exemplos:

LIN (9;1): E você conhece alunos assim, igual ao Marcelo? Hunrum. Conhece? Como eles são? Ab! Ele é da minha classe, ele chama Ruan. Meu professor antes da professora Aline, ele só ficava batendo o professor pôs ele lá pro pré de novo. Voltou ele pro pré? É. Por que ele só ficava batendo? O professor que tinha antes dessa professora? Batendo e não copiava. $\mathrm{O}$ que acontece com essas crianças que não aprendem? Eles só fica batendo nos outros, é... fazendo graça é... Só bate, faz graça, mas e aí o que acontece com eles? Ah! E aí ele vai ficar burro. E como você se sente diante de situações assim? Ah! Acho ruim.Você acha ruim? É? Bastante. Bastante? Por que? Por causa que não vou aprender, não vou ter profissão, e não vou... não vou... e a professora vai ficar chamando minha atenção bastante.

Ou ainda, o protocolo de BIB (16;6):

O que mais que a professora poderia fazer pra ajudá-lo? Tentar assim enturmar ele, fazer ele ter mais amigos. E o que você acredita que dever ser feito? Que os alunos da sala ajude ele, porque tanto... vamos supor, eu como outros alunos que se sente excluido, ia ficar mais excluido vendo os alunos todos 
assim querendo engrupar e deixando ele de lado, então acho que os alunos também deveria ajudar ele. E se ele não aprender o que pode acontecer com ele? Ab! Ele vai ficar triste ver os colegas tudo aprendendo e ele não conseguir. Pra ele é uma dificuldade o que pros outros é uma facilidade pra ele é uma dificuldade. E você conhece algum aluno que é assim? Sim, eu mesma já passei por isso de ver os alunos da minha classe aprendendo e eu mesmo querendo não consegui. E sempre que fazem grupos é sempre a mesma turma e sempre deixam o que sabe menos de lado com um grupo que sabe menos, e o grupo que sabe mais é sempre o mesmo, nunca tem a divisão de quem sabe menos com os que sabem mais e sempre é o que sabe menos com menos e o que sabe mais com mais.

Todavia, se analisarmos a questão sob a perspectiva da construção do conhecimento social, em específico, os níveis propostos por Delval (2002), percebemos que há uma dificuldade na consideração de múltiplos fatores que podem influenciar na aprendizagem, uma vez que somente uma ponta do processo é considerada - o aluno. Sabemos que o conhecimento social é construído, também, mediante as informações que recebemos do meio externo, das pessoas, no caso específico, dos professores. Essas informações podem permanecer ainda incompreendidas, sendo apenas repetidas pelos sujeitos que não as insere num sistema de compreensão maior. Muitas vezes, as falas de nossos sujeitos podem ser uma repetição daquilo que é ouvido do professor e permanecem como explicações que aqueles conseguem dar sobre a não aprendizagem. Dessa forma, os alunos podem assumir uma perspectiva mais rotulante, que só atribui responsabilidade ao discente pela não aprendizagem, até mesmo em relação a eles próprios.

É nesse sentido que Delval (2002) afirma que as explicações são baseadas nas aparências, naquilo que se percebe diretamente e, muitas vezes, estereotipadas. O estereótipo de que aquele que não aprende é indisciplinado e culpado considera apenas alguns aspectos do problema e não as diferentes variáveis possíveis.

Chamam a atenção algumas falas, como por exemplo, a de MUR (6;9) que afirma: [...] ele não quer aprender, se ele quisesse ele conseguia. Ou seja, basta querer. Podemos refletir, embora esse não tenha sido o objetivo da presente pesquisa, a respeito de como se sente uma criança em relação às próprias experiências de fracasso na escola. Se alguém 
acredita que basta ter vontade, como consegue interpretar o próprio insucesso e o próprio esforço?

As razões baseadas nos aspectos orgânicos e na família também são bastante encontradas entre adultos, professores e/ou psicopedagogos (GUIMARÃES, SARAVALI, 2006; SARAVALI, GUIMARÃES, 2007). Tal fato se deve, a nosso ver, à ampliação considerável de terminologias, rótulos e diagnósticos de doenças que explicariam a não aprendizagem discente. Muitos aspectos do intercâmbio entre as áreas da saúde e a da educação acabam servindo mais como rotuladores e/ou provocadores de preconceitos do que de ações efetivas em prol dos alunos.

Mesmo quando apresentam mais de uma explicação, que acaba enquadrando a resposta em mais de uma categoria, a grande maioria dos sujeitos une a categoria $1 \mathrm{com}$ a 2 , ou seja, a aprendizagem não ocorre porque há indisciplina e desinteresse. Vejamos excertos de dois protocolos de sujeitos de 6 e 16 anos:

FMO (6;8): O que você acha dessa situação? Ele tem que sentar numa dupla que sabe fazer tudo e pode ensinar ele. O que você acha que está acontecendo com essa criança? Eu acho que ele tem preguiça. [...] Por que será que ele não aprende? Porque ele deve ter, tá faz̧endo muita bagunça e não quer aprender.

FRA $(16 ; 5):$ O que você acha que pode estar acontecendo com o Marcelo? Ah! Ele deve ter algum... alguma dificuldade... pra aprender. Que tipo de dificuldade? Ab! Ele deve ser um aluno que... que não... não quer aprender que não presta atenção, ele não tem curiosidade em saber o que tá se passando...

É somente com o avanço da idade que podemos notar uma tentativa de consideração maior de outros fatores independentes do próprio aluno e/ou da sua família, tais como aqueles apontados nas categorias 5 e 6 . Nelas, sobretudo a 6 , os entrevistados parecem perceber a aprendizagem como uma questão mais ampliada, nem sempre dependente da vontade do aluno. Considerando as categorias 4, 5 e 6, temos somente 19 respostas que retiram do aluno a responsabilidade sobre a não aprendizagem. 
Tomando-se por referência que, na presente pesquisa, analisamos as interpretações sobre a não aprendizagem pela ótica da construção do conhecimento social, notamos que a análise das razões pelas quais um aluno não aprende vai, paulatinamente, agregando novas perspectivas, dessa forma, o sujeito passa a não ser taxado como único culpado e outros elementos do mundo social aparecem. É o caso, por exemplo, da explicação de GIO (16;7): [...] às vez̧es pode ser o próprio professor um pouco também né que às vezes não sabe explicar assim pra ele do jeito que ele queria que aconteceria.

Embora, no presente artigo, nossa pretensão seja a de explorar apenas o primeiro eixo da análise da história, é possível tecer alguns comentários em função das respostas obtidas junto aos outros eixos temáticos, buscando compreender melhor o nível de compreensão que os participantes apresentaram sobre a temática. O que seria uma percepção mais elementar ou de nível I? O que definiria um nível II na ideia de não aprendizagem? E uma concepção mais elaborada, por exemplo, de nível III? Há concepções mais elaboradas entre os sujeitos mais velhos? Como ocorre essa evolução?

Ao pensarmos nas etapas propostas por Delval (2002), devemos considerar que elas se referem a toda uma forma de olhar os fenômenos sociais, que, no caso do presente instrumento, se manifestará nos diferentes eixos temáticos definidos para a análise da história. Concordamos, portanto, com Delval (2002) quando, ao explicar a composição dos níveis de compreensão da realidade social, aponta:

Cada indivíduo apresenta uma unidade e uma coerência interna em suas respostas, ainda que em alguns casos não seja fácil observá-las à primeira vista. Mesmo as contradições são coerentes, se é que se pode falar assim, pois correspondem a seu nível de desenvolvimento e são características desse estágio. Mas isso se perde na análise do conjunto de respostas dos sujeitos de uma determinada idade. Contudo, quando analisamos as respostas, devemos procurar considerar cada indivíduo em sua globalidade, como uma unidade. A análise de respostas isoladas, ao contrário, facilita a fragmentação do sujeito e não permite ver essa coerência. (DELVAL, 2002, p.220).

Para o primeiro nível, consideramos aquelas respostas que definem a não aprendizagem somente como responsabilidade do personagem da história. Nessas respostas, encontram-se as referências ao não 
gostar de estudar, não querer, não se dedicar, ser indisciplinado (fazer bagunça, conversar, não prestar atenção), não estudar direito etc. Os sujeitos interpretam a questão atribuindo ao aluno a responsabilidade de "saber" ou "não saber" aprender.

A responsabilização do aluno indica também a interpretação de que o professor sempre cumpre seu papel corretamente, o que é bem característico desse nível, por exemplo:

JEN (6;5): $O$ que você acha que acontece que ele não consegue aprender? ... Ele tem que prestar muita é... como que é... prestar muita... coisa na professora. Muita atenção? É muita atenção na professora, porque a professora é muito inteligente e sabe tudo.

Embora nosso alvo não seja o desenvolvimento moral, não devemos desvincular as questões sociais das de ordem moral. O próprio Delval (2007) nos apresenta como aspectos a serem estudados dentro do conhecimento social, as normas que regulam a sociedade, a organização e definição dos papeis sociais etc. No caso da resposta de JEN $(6 ; 5)$ e da atribuição de responsabilidade somente ao aluno, vemos como os sujeitos mantém uma relação heterônoma com o assunto. Assim o adulto, isto é, o professor, desempenharia sempre o seu papel da melhor forma, isso não seria questionado num nível I. É somente com o avanço na construção dessas representações que os sujeitos conseguem, por exemplo, analisar a situação de não aprendizagem a partir da perspectiva do professor também.

Nesse sentido, ao mesmo tempo que se considera como essencial a conduta do aluno, a ação do professor é sempre vista da melhor forma. Isso evidencia boas expectativas em relação ao mestre e o caráter inquestionável das ações do adulto. Por exemplo, no eixo resolução, ao analisarem o papel do professor, esses sujeitos acreditam que basta ao professor ensinar.

Todavia, ao descreverem esse ensino, os sujeitos apenas repetem algumas ações sem considerarem que as mesmas podem continuar sendo infrutíferas: falar, repetir até aprender, mandar para o reforço, etc. DAN (6;4) diz: "Explicar toda hora, ele vai ficando 'cabeça boa"'. A intervenção do mestre pode ser também de forma mais enérgica a fim de resolver a questão disciplinar que, consequentemente, resolveria o problema 
da aprendizagem. Esse tipo de interpretação, também foi encontrado nos estudos de Delval sobre os direitos das crianças (DELVAL; PADILLA, 1997).

Mesmo quando os sujeitos elencam outras formas de intervenção, de outras pessoas ou instituições, as ações repetem as já executadas (e apontadas pelos sujeitos) por professores, por exemplo, os pais podem explicar, podem ajudar na tarefa; os amigos falam para estudar etc. LFS (6;5) explica: "A escola fazia ela aprender." E JOH (6;11): "O amigo do lado. Ele acaba, ai vai mostrando as letras pra ele pra ir rapidinho."

A referência aos amigos, nesse nível, apenas reproduz a ação do professor. Essa intepretação é semelhante, novamente, à que Delval realizou em pesquisas sobre os direitos das crianças (DELVAL; PADILLA, 1997). Numa das situações utilizadas, os sujeitos deveriam analisar uma história de uma criança que não podia ir à escola, pois os pais a obrigavam a trabalhar. Quando solicitada a refletir sobre uma possível resolução para a questão, a maioria afirma que é necessário conversar com os pais, no entanto, se estes não concordarem nada poderia ser feito. Esse tipo de resolução foi considerada de nível I. Algumas crianças indicavam que se poderia recorrer a outras pessoas, tais como vizinhos, professores etc. No entanto, quando solicitadas a explicarem sobre o que estas pessoas poderiam fazer, os sujeitos, no nível I, afirmavam: "conversar com os pais". A resolução encaminhada buscava então o convencimento da autoridade que continuaria a manter a palavra final.

No caso da presente pesquisa, entendemos que, nesses protocolos considerados de nível I, o aparecimento de outras pessoas na tentativa de se ajudar o aluno percorre o mesmo caminho que na pesquisa citada sobre os direitos das crianças. Dessa forma, as pessoas repetirão as ações dos mestres; os amigos que aparecem também teriam essa função, como nos diz JOH $(6 ; 11):$ [...] vai mostrando as letras pra ele pra ir rapidinho." Esses elementos são diferentemente apresentados quando se tratam de respostas mais elaboradas, como as de nível III, conforme veremos mais adiante.

A ideia de aprendizagem nesse nível é associada somente a conteúdos escolares e/ou a frequência à escola. Não se pensa a aprendizagem de uma outra forma, fato que acontece com os participantes enquadrados no nível III. Aprender é, portanto, saber fazer as tarefas, tirar notas boas nas provas, não reprovar e ocorre com quem frequenta 
a escola. Quem não aprende é porque não a frequenta. Não se considera também a aprendizagem de maneira atemporal, isto é, ela ocorre ou não somente no tempo escolar. Assim é que ao serem perguntados, no eixo "desfecho", sobre o que aconteceria se o aluno não aprendesse, os sujeitos respondem repetir de ano, tirar nota baixa, ir para a diretoria, não conseguir fazer as atividades. Há também uma interpretação sacramentada sobre a questão. Não há meio termo, nem processos para se considerar, mas sim extremos, por exemplo, se não aprender não vai saber nada, vai ficar burro etc.; um exemplo:

JEN (6;5): "[...] ele não vai aprender nunca mais. Se ele não trazer a tarefa todo dia, ele não vai aprender nunca mais e vai ficar muito ruim e não vai aprender nada e quando umas pessoas perguntar as coisas ele não vai saber nada.'

O nível II é considerado mais avançado, mas não mais importante do ponto de vista das crenças dos sujeitos. Nele, podemos observar que há uma transformação paulatina e o aparecimento de novos elementos. Dessa forma, nas explicações dos sujeitos, novos dados começam a surgir e o raciocínio vai se tornando menos perceptivo, ampliando-se as interpretações.

As justificativas para a não aprendizagem ainda se centram em algumas questões mais aparentes, considerando o aluno como o maior responsável. No entanto, os problemas elencados sugerem que não somente uma ação da criança resolveria o problema. É o caso, por exemplo, da menção a algum aspecto orgânico, como um problema mental.

Consequentemente, um outro tipo de intervenção começa a ser relacionada. Outras pessoas podem auxiliar, como um médico, um psicólogo etc. As ações da professora também não são vistas de forma unilateral e um atendimento diferenciado ou específico passa a ser considerado. Assim é que os sujeitos mencionam a necessidade de uma atenção especial a esse aluno, de um cuidado maior, realização de trabalhos e/ou provas diferenciados. As ideias contidas aqui parecem indicar o início da consideração de processos, a necessidade, por exemplo, do professor se dedicar porque o aluno tem alguma dificuldade, porque acha aquilo difícil etc.

A aprendizagem começa a não ser relacionada somente a conteúdos escolares, mas outros aspectos também passam a ser apontados. 
A questão do não aprender também é desvinculada do imediatismo do nível anterior, encontrado tanto entre os sujeitos mais novos como nos mais velhos. Novos elementos aparecem, como não conseguir um bom emprego, não ter um bom futuro, envolver-se com drogas etc.; ainda que aprender/não aprender seja considerado como a razão para tudo, o que mostra uma dificuldade com as explicações, traço evidente do nível II.

Vejamos trechos de dois protocolos classificados como nível II:

LBH (12;5): O que você acha que está acontecendo com o Marcelo? Ab! Tem algum problema na familia dele ou ele tem alguma dificuldade de aprender era melhor ele ir pra outra escola que os professores já sabem como lidar com pessoas desse jeito. Por que será que ele não aprende? Ou ele tem alguma... alguma doença que prejudica isso... é alguma coisa assim que não ajuda ele a pensar a refletir sobre as coisas. Quem você acha que poderia ajudá-lo? Primeiro os pais dele incentivando ele a fazer as coisas e depois os professores ajudando mais ele dando mais atenção pra ele. Como que os professores poderiam ajudar? Ah! passando acho que mais atividades pra começar do jeito dele pra depois pra ele acompanhar na dos outros porque acho que ele não consegue acompanhar pra ele tem que fazer do começo de novo e ir indo até ele conseguir chegar a altura das outras pessoas. E se ele não aprender, o que pode acontecer com ele? Ab! Ele não vai ter um bom trabalho, não vai ser possivel ele entrar numa faculdade boa porque ele não vai saber das coisas.

TAI (16;4): Eu acho que ele deve tá com algum problema ou deve tá trabalhando talvezpra poder ajudar a familia. Que tipo de problema que poderia estar acontecendo com ele? Ab! Alguma dificuldade a familia pode tá tendo em casa. Deve ser uma família humilde que não tenha... não tenha como ele só estudar fazer o dever de casa fazer as atividades escolares e tenha que fazer outras atividades pra ajudar a familia. Quem você acha que poderia ajudá-lo? Ab! Sua própria família orientando ele a ter um estudo que agora ele pode tá ajudando a familia mas com o estudo pra frente ele pode ajudar muito mais. E a escola pode ajudar? Ou a escola proporcionando horários melhores pra ele os professores ajudando ele dando menos atividade ou instruindo melhor dando uma atenção maior. Por que será que o Marcelo não aprende? Ah! pode ser porque ele às vezes pelo trabaIho talvez fique cansado ou não tenha muita atenção na escola fique cansado do tra- 
balho vai pra escola aí não tenha tanto... tanta atenção nas aulas. O que você acha que a professora podia fazer pra ajudar ele? Eu acho que ela poderia ter uma atenção especial com ele de saber que ele tem dificuldade de aprender ou o problema de às vezes chegar atrasado ou ficar cansado ela poderia dar uma atenção maior pra ele. Se ele não aprender o que você acha que pode acontecer com o Marcelo? Ab! Eu acho se ele aprender... ele não aprender que nem se ele tiver passando por uma dificuldade em casa eu acho que pra frente pode ser tornar pior porque se ele aprende ele pode melhorar a situação.

Poucos sujeitos da nossa amostra apresentaram respostas características do nível III (5\%). É, portanto, difícil retratar com exatidão como seria esse tipo de interpretação sobre a questão do não aprender. Considerando os elementos apontados por Delval (2002) e as respostas diferenciadas desses 4 sujeitos, identificamos o nível III como uma ampliação considerável das variáveis envolvidas, bem maior que no nível II.

Nesse sentido, há inúmeras razões para que um aluno não aprenda e fatores mais complexos são apresentados, como, por exemplo, a exclusão escolar e social. Não há mais somente ênfase em questões aparentes.

Há também várias possibilidades de intervenção e os sujeitos apontam, às vezes, na mesma resposta, a escola, a professora, a família, outros profissionais e os amigos, como possíveis agentes. Todavia, as ações desses vários elementos são bem diferentes daquelas apresentadas no nível I. Assim, por exemplo, os amigos conversam, compreendem, apoiam, não excluem, tiram as dúvidas junto com os professores etc. Oi ainda, quando indicam questões familiares como problemas existentes, afirmam que a escola necessita se preocupar e considerar isso também. Aparece o início dos acordos sociais, ou seja, o estabelecimento de compromissos entre aqueles que desempenham seus papéis sociais. Assim é que, por exemplo, LCS (16;6) explica: Ab! Eu acho que falta vontade dele e também... se não falta vontade, se ele se esforça, o professor tem que tentar explicar melhor pra ele, pra ver se ele consegue se adequar e ficar bem na aula."

Aparecem também diferentes consequências para o não aprender, há, inclusive, relações com sentimentos, com capacidade de interagir, com a percepção de si no grupo escolar e social.

$\mathrm{O}$ trecho a seguir mostra uma resposta considerada como de nível III. 
NLI (16;6): O que você acha dessa situação? Ab! Talvez ele tenha algum tipo de dificuldade e talvez... as pessoas não ajudam ele da forma que ele precisa. O que você acha que pode estar acontecendo com ele? ... Ah!... O que que tá acontecendo? Ab!... Uma pessoa assim... que não tem estimulo de alguém... uma pessoa que não tem ninguém a volta dele que fique estimulando ele pra ele aprender pra ele fazer as coisas. Quem que você acha que poderia ajudálo então? Amigos. Os amigos? De que forma que os amigos poderiam ajudar? Ab!... Conversando tentando ver o lado dele tentando ver o que tá acontecendo com ele pra achar o melhor jeito de poder ajudar. E a escola? Acho que a mesma coisa. A mesma coisa? Tentando saber o que tá acontecendo. E o que você acha que a professora poderia fazer? ... Assim não tratar de forma diferente porque todo mundo é igual, mas sei lá, conversar assim eu acho que é tudo um conjunto tentar entender o que tá acontecendo pra achar a maneira de ajudar ele a maneira certa de ajudar ele. Se ele não aprender o que vai acontecer com ele? Ab! Ele vai tá uma pessoa excluida da sociedade por não ter o conhecimento, excluido do mercado de trabalho... essas coisas assim.

A tabela 2, a seguir, mostra a distribuição dos sujeitos pelos níveis de compreensão da realidade social.

Tabela 2. Distribuição dos sujeitos nos níveis de compreensão da realidade social

\begin{tabular}{c|lllll|c|c} 
NÍVEIS & \multicolumn{5}{|c|}{ IDADES } & TOTAL & $\%$ \\
\hline & $\mathbf{6}$ & $\mathbf{9}$ & $\mathbf{1 2}$ & $\mathbf{1 6}$ & & \\
\hline I & 20 & 19 & 10 & 6 & 55 & 68,7 \\
\hline II & - & 1 & 10 & 10 & 21 & 26,3 \\
\hline III & $\cdot$ & $\cdot$ & $\cdot$ & 4 & 4 & 5,0
\end{tabular}

Podemos observar um dado que vem se confirmando em estudos evolutivos realizados no contexto brasileiro, qual seja, mesmo entre sujeitos de idades mais avançadas, poucos são aqueles que apresentam níveis mais elaborados de compreensão da realidade social (CANTELLI, 2000; BARROSO, 2000; MONTEIRO, 2010). Os dados dessas pesquisas indicam que esses sujeitos permanecem por muito tempo com crenças incompletas sobre conteúdos diferentes da realidade social. 
Esse fato, a nosso ver, sugere a necessidade de realização de diferentes pesquisas, sobretudo as de caráter evolutivo e/ou aquelas com sujeitos mais velhos, a fim de se avaliar a confirmação ou não dessa característica nos sujeitos brasileiros, bem como a quais conteúdos da realidade social ela se aplica. Há também que se considerar a necessidade de trabalhos que analisem outras dimensões do desenvolvimento dos sujeitos em relação à construção do conhecimento social, entre elas, o desenvolvimento cognitivo.

É importante considerar que a interpretação e o sentido que atribuímos às diferentes questões direcionam nossas ações, por isso, um conhecimento de nível I, que apresenta dificuldades em considerar processos, que desconsidera a existência de conflitos e não consegue propor resoluções efetivas, é um conhecimento incompleto de uma questão social. Caso ele assim permaneça na mente do sujeito poderá afetar sua interação e ação em relação a várias outras questões sociais. Soma-se a isso o fato de que ao estudarmos a evolução dessas representações, podemos compreender melhor certas interpretações existentes em nossa sociedade e provenientes dos adultos. A esse respeito, Delval (2007) afirma:

Pero estudiar cómo se forman esas ideas no es um mero entretenimiento o una curiosidad, pues las representaciones del mundo social determinam lo que los sujetos hacen y pueden hacer, cómo actuan. Y para entender las concepciones de los adultos es esencial conocer su proceso de formación. Estamos convencidos, por tanto, de que estudiar la génesis de los conceptos sociales tiene una enorme utilidad para entender las ideas adultas sobre la sociedad y es un requisito indispensable para desarollar una epistemologia genética de las ciências sociales. (p.49-50)

A cada representação que o indivíduo precisar elaborar, ele recorrerá aos elementos que já possui, fruto e/ou pertencentes a outras representações que igualmente vai elaborando da realidade social. Sendo assim, os elementos são combinados, relacionados, reelaborados formando as explicações ou representações que os sujeitos possuem. Para Delval (2007) não se trata apenas de nos preocuparmos com a compreensão a respeito de um ou outro conteúdo escolar, mas de entendermos como um sujeito se torna adulto dentro de uma sociedade determinada e como adquire a ideologia dessa sociedade, assim como as instituições sociais, as regras de funcionamento social etc. 
Em específico sobre as questões abordadas na presente pesquisa, trata-se de compreender como os alunos conseguem perceber questões que compõem o mundo do qual fazem parte e sobre o qual dedicam grande parte de suas vidas: o escolar.

\section{Algumas considerações}

A relevância de estudos na área do conhecimento social é inquestionável e, por se tratar de uma temática relativamente nova no nosso contexto, torna-se fundamental, também, refletir sobre as novas necessidades e as aberturas que as pesquisas estão nos apresentando. Nesse sentido, os resultados dessas pesquisas também devem nos servir para importantes reflexões e orientações sobre a prática pedagógica.

O objetivo central do presente trabalho consistiu em investigar as ideias de crianças e adolescentes a respeito do não aprender. Ao tratarmos dessa questão sob a ótica da construção do conhecimento social, assumimos que, apesar de se tratar de um conteúdo rotineiro e cotidiano para alunos e alunas, pois compõe o leque de suas experiências, sobretudo, escolares, haverá uma elaboração gradual que agrega paulatinamente novos e mais complexos elementos. $\mathrm{O}$ avanço nessa elaboração é que permite ao sujeito compreender melhor a realidade que o cerca ou a problemática em questão.

Foi possível observar a existência de ideias bastante singulares sobre o cotidiano escolar e sobre os aspectos envolvendo a não aprendizagem. Algumas dessas ideias se modificam conforme a idade dos sujeitos, outras não. Nesse sentido, um aspecto interessante, apresentado por nossos dados, se deve ao fato de que, mesmo em idades mais avançadas, os participantes, em sua grande maioria, não apresentam interpretações correspondentes a níveis mais avançados de compreensão da realidade social, como os níveis II e III.

Dar voz aos estudantes sobre o que pensam em relação ao aprender e não aprender é tão importante quanto tentar explicar ou resolver uma situação de não aprendizagem. Os elementos, as explicações e justificativas são muito ricas e nos remetem ao universo dos alunos: como enxergam a questão, o que valorizam, o que desconsideram etc. 
O que foi possível obervar, em nossos protocolos, é que os alunos nos trazem elementos muito ricos de suas vivências escolares, por exemplo, falam de indisciplina e motivação, acreditam no papel do professor e o valorizam, enaltecem a importância da escola na vida dos alunos e das pessoas de uma maneira geral. Entretanto, a maneira como interpretam a situação envolvida na história, bem como conseguem justificá-la e/ou resolvê-la é característica do primeiro nível de compreensão da realidade social. Assim, as respostas não conseguem coordenar diferentes perspectivas do problema, não analisam os papeis sociais de forma coordenada, dissociando-os, bem como excluem processos ocultos que precisam ser inferidos.

A falta de concepções, características do nível III, em relação a estas questões indica também que esse tipo de conhecimento não se constrói por simples maturação e que é preciso reorganizar as ações didáticas, levando-se em consideração os processos percorridos para a apropriação dos sistemas sociais. Portanto, alguns elementos que tornam bem mais complexa a interpretação sobre as situações de sala de aula precisam ser construídos/considerados pelos sujeitos, isso significa um raciocínio mais elaborado sobre esses temas. Dessa forma, ao se pensar, por exemplo, na relação ensino/aprendizagem - professor/ aluno é necessário considerar: quando uma professora ensina e um aluno não aprende, o que está ocorrendo? Quais inúmeros fatores podem provocar/influenciar esse quadro?

As informações provenientes dos mais velhos, pais e mestres, dos meios de comunicação e das interações sociais, formam o conjunto de elementos que ajudam a compor a interpretação que o sujeito possui. Todavia, é preciso levar em conta as condições de organização e de possibilidade de atribuição de sentido a esses elementos que os indivíduos possuem e/ou recebem. É curioso notar que muitas representações e crenças, apresentadas pelas crianças e pelos jovens da presente pesquisa, coincidem com aquilo que adultos pensam, tal como mostrou os trabalhos de Guimarães e Saravali (2006) e Saravali e Guimarães (2007). Essas respostas assumem um caráter rotulante e unilateral, de tal forma que outras perspectivas, fatores e até mesmo conflitos não são considerados. Assim, o quadro de não aprendizagem sempre ocorre por falta de atenção, motivação e disciplina dos próprios alunos. Quando são elencados fatores diferentes ou externos ao pró- 
prio aluno, a família é a maior culpada. Há pouquíssimas referências e/ou mesmo análises sobre todo o processo envolvendo a aprendizagem, sobretudo, as próprias condições de ensino. Quando os sujeitos se arriscam a discutir questões referentes ao ensino, o fazem, analisando uma ponta do processo; assim, uma metodologia adequada, uma aula melhor, quase que como mágica, resolveriam o problema. Esses dados, analisados sob a perspectiva da construção do conhecimento social, sugerem que indivíduos adultos (GUIMARÃES; SARAVALI, 2006, SARAVALI; GUIMARÃES, 2007) e crianças e adolescentes, no caso do presente trabalho, permanecem com ideias bastante simplistas de fenômenos sociais complexos.

As crenças sobre a não aprendizagem podem influenciar como os sujeitos avaliam a si próprios em relação à mesma questão. Portanto, quando um indivíduo responsabiliza o próprio aluno por uma aprendizagem que não ocorre, tende a pensar o mesmo sobre si mesmo quando está na mesma situação. Em diferentes momentos de nossa análise, conforme apresentamos, foi possível notar como alguns sujeitos se identificam com a questão da não aprendizagem abordada na entrevista. É preciso considerar as implicações decorrentes desse dado. Quando uma criança não aprende não tenderia ao mesmo tipo de raciocínio? $\mathrm{Ou}$ seja: de alguma forma não se culpariam? Quais as consequências para a formação do seu autoconceito e qual a relação que estabelecem com a aprendizagem de uma maneira geral?

Nesse sentido, cumpre destacar que os sujeitos de nossa amostra foram escolhidos aleatoriamente, ou seja, não sabemos se havia na amostra alunos com problemas para aprender. Tal fato sugere a necessidade e importância da réplica do nosso estudo junto a essa população: o aluno que não aprende.

Sabemos que os estudantes vivenciam cotidianamente essas questões e constroem, simultaneamente, crenças sobre si e os outros em relação a esses temas. Compreender, portanto, como o aluno percebe, ao longo do seu desenvolvimento, o não aprender, é fundamental para que o próprio professor possa auxiliá-lo nesse processo, sobretudo, quando a aprendizagem não ocorre.

Assim como no trabalho para construção de diferentes noções sociais, é preciso haver um espaço para que o aluno fale sobre a escola, sobre o professor, sobre a aula, auxiliando na compreensão e coordena- 
ção de diferentes processos. É somente a partir da análise de diferentes situações, com a troca de pontos de vistas diversos e perspectivas diferentes que os indivíduos podem avançar na interpretação do mundo social. Além disso, compreender melhor uma situação de não aprendizagem pode auxiliar o próprio sujeito na resolução de um quadro desfavorável que o afete, por exemplo.

Ao discutirem sobre a importância de se conhecer como os estudantes pensam o aprender, Grácio, Chaleta e Rosário (2007) afirmam que analisar e debater nas salas de aula as concepções dos alunos sobre o tema é uma higiene educativa que deveria apoiar qualquer intervenção. Para os autores, a compreensão do aprender, na perspectiva dos protagonistas do processo, permite estudar e agilizar o fenômeno da aprendizagem, bem como fundamentar ações educativas que promovam um pensamento mais profundo e um controle maior sobre a própria aprendizagem.

Esses aspectos certamente se aplicam também para as interpretações sobre a não aprendizagem.

Nesse sentido, acreditamos que a presente pesquisa traz contribuições para o campo pedagógico, psicológico e psicopedagógico, pois mostra como alunos pensam questões relacionadas ao não aprender. Pretendemos, também, com esse estudo, contribuir para a compreensão dos processos percorridos na construção do conhecimento social, em especial no contexto brasileiro. 


\section{NOTAS}

1 Financiada pelo CNPq, Edital Universal.

2 Analisada e aprovada pelo Comitê de Ética em Pesquisa, processo número 642/2009.

3 Ainda que estejamos fazendo referências às idades, é importante ressaltar que são sempre referências, isto é, idades aproximadas, pois as construções serão sempre fruto de uma interação (e da qualidade da mesma) indissociável entre sujeito e meio físico e/ou social. Assim, a idade não define o estágio do desenvolvimento cognitivo; nem o nível de compreensão da realidade social, essa última ideia confirmada pelos nossos próprios dados apresentados aqui.

4 Embora a entrevista tenha algumas questões padronizadas, a utilização do método clínico-crítico prevê que, a partir das respostas dos sujeitos, outras perguntas sejam feitas. Por isso, utilizamos o termo "algumas delas" e não "são elas". O sujeito pode também, ao longo da entrevista, manifestar sua crença desencadeada e/ou espontânea sobre a questão, sem que isso lhe seja perguntado diretamente. É a análise de toda a entrevista que permite ao experimentador ter uma ideia mais fiel do pensamento do sujeito.

5 A frequência de respostas não corresponde ao total de sujeitos da pesquisa (80), já que um mesmo sujeito poderá fornecer, em uma mesma resposta, explicações decorrentes de uma ou mais categorias diferentes. Em decorrência disto, o percentual total pode ultrapassar $100 \%$.

\section{REFERÊNCIAS}

ARAÚJO, A.S.; GOMES, L.R. A noção de mobilidade social em adolescentes. Educar em revista. Curitiba: Editora da UFPR, n.38, p.193-204, 2010.

ARAÚJO, R. M. B. O desenvolvimento do pensamento econômico em crianças: avaliação e intervenção em classes de $3^{a}$ e $4^{a}$ série do Ensino Fundamental. Tese (doutorado em educação). Faculdade de Educação da UNICAMP - Campinas, 2007.

ASSIS, O. Z. M. Conhecimento físico, conhecimento lógico-matemático e conhecimento social. In: ASSIS, Mucio e ASSIS, Orly (org.) PROEPRE: Fundamentos Teóricos e prática pedagógica para a educação infantil. Campinas: Faculdade de Educação, Unicamp, 2003. p.78-104.

BAPTISTELLA, E. C. F. A compreensão de um conteúdo de um comercial televisivo na infância. Dissertação (mestrado em educação) Faculdade de Educação da UNICAMP Campinas, 2001.

BARROSO, L.M.S. As ideias das crianças e adolescentes sobre seus direitos: um estudo evolutivo à luz da teoria piagetiana. Dissertação (mestrado em educação). Faculdade de Educação, UNICAMP, Campinas, 2000.

BORGES, R. R. A construção da noção de família em crianças pré-escolares. Dissertação (mes- 
trado em educação) Faculdade de Educação, UNICAMP, Campinas, 2001.

BRAGA, A. A influência do projeto "A formação do professor e a educação ambiental" no conhecimento, valores, atitudes e crenças nos alunos do ensino fundamental. Dissertação (mestrado em educação) Faculdade de Educação, UNICAMP, Campinas, 2003.

CAMARGO, P.S.A.S.C. Percepções de alunos jovens e adultos sobre o processo de ensino-aprendizagem. Dissertação (mestrado em educação). Faculdade de Educação, UNICAMP, Campinas, 2005.

CANTELI, V. C. B. Um estudo psicogenético sobre as representações de escola em crianças e adolescentes. Dissertação (mestrado em educação). Faculdade de Educação, UNICAMP, Campinas, 2000.

CANTELLI, V.C.B. Procedimentos utilizados pelas famílias na educação econômica de seus filhos. Tese (doutorado em educação) Faculdade de Educação, UNICAMP, Campinas, 2009. CORSINI, C.F. Dificuldades de Aprendizagem: representações sociais de professores e alunos. Dissertação (mestrado em Ppsicologia). PUCCAMP, Campinas, 1998.

DELVAL, J La representacion infantil del mundo social In: TURIEL, E., ENESCO, I. y LINAZA, J. (comps). El mundo social em la mente del nino. Madrid: Alianza, 1989.

DELVAL, J. Introdução à prática do método clínico: descobrindo o pensamento da criança. Tradução de Fátima Murad. Porto Alegre: Artmed, 2002.

DELVAL, J. Aspectos de la construcción del conocimiento sobre la sociedad. Educar em revista. Curitiba: Editora da UFPR, n.30, p.45-64, 2007.

DELVAL, J.; PADILLA, M.L. El desarrollo del conocimiento sobre la sociedad. 1997 (mimeo). DENEGRI, M. A construção do conhecimento social na infância e a representação da pobreza e desigualdade social: desafios para a ação educativa. In: Encontro Nacional de Professores do PROEPRE, 15, 1998, Águas de Lindóia. A criança e a escola. Anais... Campinas: UNICAMP/FE/LPG, p.43-54, 1998.

GODOY, E. A representação étnica por crianças pré-escolares: um estudo de caso à luz da teoria piagetiana. Dissertação (mestrado em educação). Faculdade de Educação, UNICAMP, Campinas, 1996.

GRÁCIO, M.L.F.; CHALETA, M.E.R.; ROSÁRIO, P. Conceptualizações sobre o aprender ao longo da escolaridade. Interacções. n.6, p.197-214, 2007. Disponível em: http://www.eses.pt/interaccoes

GUIMARÃES, T. As idéias infantis a respeito da escola e do professor: um estudo comparativo acerca da construção do conhecimento social em ambientes sócio-morais construtivistas e ambientes tradicionais. Iniciação Científica - Relatório Final de Pesquisa, FAPESP, 2007.

GUIMARÃES, T. Intervenção pedagógica e noções sobre o meio ambiente: a construção do conhecimento social à luz da epistemologia genética. Dissertação (Mestrado em Educação). Faculdade de Filosofia e Ciências, Universidade Estadual Paulista, Marília, 2012.

GUIMARÃES, K.P.; SARAVALI, E.G. Concepções dos alunos do curso de psicopedagogia a respeito das dificuldades de aprendizagem. Educação Temática Digital - UNICAMP. v.8, n.1, dez 2006. p.187-207.

MARIANO, M.L. Representações Sociais de jovens sobre sucesso e sobre fracasso e sua contribuição para o ensino/ aprendizagem de História. Dissertação (mestrado em psicologia educacional). Centro Universitário FIEO, Osasco-SP, 2009.

MONTEIRO, T. A. Um estudo evolutivo sobre as ideias de crianças e adolescentes a respeito da Educação em Revista | Belo Horizonte | v.29 | n.03 | p.143-176 | set. 2013 
violência urbana. Relatório Final de Pesquisa (Iniciação Científica) -, FAPESP, 2010. MOSCOVICI, S. A representação social da psicanálise. Rio de Janeiro: Zahar, 1978.

OSTI, A. Representações de alunos e professores sobre ensino e aprendizagem. Tese (doutorado em educação). Faculdade de Educação, UNICAMP, Campinas, 2010.

OTHMAN, Z.A.S. Compreensão da noção de lucro em crianças e adolescentes vendedores e não vendedores de rua de Curitiba. Dissertação (mestrado em educação). Universidade Federal do Paraná, Curitiba, 2006.

PIAGET, J. O raciocinio na criança. Tradução: Valerie Chaves. Rio de Janeiro: Record, 1967.

PIAGET, J. Psicologia e pedagogia. Tradução: Dirceu Accioly Lindoso e Rosa Maria Ribeiro da Silva. Rio de Janeiro: Forense universiária, 1976.

PIAGET, J. A representação do mundo na criança. Tradução Rubens Fiúza. Rio de Janeiro: Record, 1979.

PIAGET, J. O juízo moral na criança. 2ed. Tradução: Elzon Lenardon. São Paulo: Summus, 1994.

PIECZARKA, T. Concepções de desigualdade social e mobilidade socioeconômica de adolescentes de escola pública de Curitiba. Dissertação (mestrado em educação). Universidade Federal do Paraná, Curitiba, 2009.

PIRES, L.; ASSIS, O. Z. M. As representações das crianças sobre a noção de lucro: a construção do conhecimento social numa perspectiva construtivista. In: Encontro Nacional de Professores do PROEPRE, 22, 2005, Águas de Lindóia. Educação e Cidadania. Anais... Campinas: UNICAMP/FE/LPG, p.471, 2005.

SARAVALI, E. G. Trabalhando os direitos das crianças numa sala de educação infantil. In: Reunião Anual da ANPED, 28. Caxambú. Quarenta anos da Pós-Graduação em Educação no Brasil: produção de conhecimento, poderes e práticas. Anais.... v.1. p.1-25, 2005.

SARAVALI, E.G.; GUIMARÃES, K.P. As dificuldades de aprendizagem na visão de futuros educadores: o que dizem estudantes do curso de pedagogia? In: IX CONGRESSO ESTADUAL PAULISTA SOBRE FORMAÇÃO DE EDUCADORES, 9. Águas de Lindóia. A articulação dos saberes na sociedade atual: o papel do educador e sua formação. Anais... São Paulo: UNESP, 2007. v.1. p.94-104.

SILVA, A.P.F. Reprovados, indisciplinados, fracassados: as micro-relações de insucesso escolar na perspectiva do "aluno problema". Tese (doutorado em educação). PUC-SP: São Paulo, 2009. SILVA, M.O da. Representações de crianças e adolescentes sobre trabalbo numa perspectiva piagetiana. Dissertação (mestrado em economia doméstica). Universidade Federal de Viçosa, Viçosa, 2009.

SIRINO, M.F. Repensando o fracasso escolar: reflexões a partir do discurso da criança-aluno. Dissertação (mestrado em psicologia). Faculdade de Ciências e Letras, UNESP, Assis, 2002.

TORTELLA, J. C. B. Amizade no contexto escolar. Dissertação (mestrado em educação). Universidade Estadual de Campinas, Faculdade de Educação, 1996.

TORTELLA, J. C. B. A representação de amizade em díades de amigos e não amigos. Tese (doutorado em educação). Universidade Estadual de Campinas, Faculdade de Educação, 2001.

TREVISOL, M.T.C. A construção do conbecimento social um estudo dos modelos organizadores Educação em Revista | Belo Horizonte | v.29 | n.03 | p.143-176 | set. 2013 
do pensamento em sujeitos entre 8 e 14 anos. Tese (doutorado em psicologia escolar e do desenvolvimento humano). Instituto de Psicologia - USP: São Paulo, 2002.

Recebido: $15 / 03 / 2012$

Aprovado: $29 / 04 / / 2013$

Contato:

Universidade Estadual Paulista Julio de Mesquita Filho

Departamento de Psicologia da Educação

Avenida Higyno Muzzi Filho, 737

CEP $17525-900$

Marília | SP | Brasil 